\title{
Critical appraisal of TNM versus HKU staging system for postoperative prognostic evaluation of hepatocellular carcinoma
}

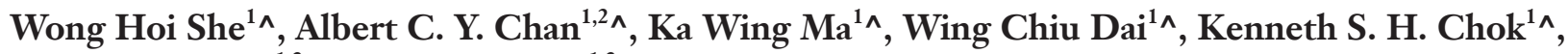 \\ Tan To Cheung ${ }^{1,2 \wedge}$, Chung Mau Lo ${ }^{1,2 \wedge}$
}

${ }^{1}$ Department of Surgery, The University of Hong Kong, Hong Kong, China; ${ }^{2}$ Department of Surgery, The University of Hong Kong-Shenzhen Hospital, Shenzhen, China

Contributions: (I) Conception and design: WH She, ACY Chan; (II) Administrative support: ACY Chan, TT Cheung, CM Lo; (III) Provision of study materials or patients: All authors; (IV) Collection and assembly of data: WH She, KW Ma, WC Dai, KSH Chok; (V) Data analysis and interpretation: WH She, ACY Chan; (VI) Manuscript writing: All authors; (VII) Final approval of manuscript: All authors.

Correspondence to: Dr. Albert C. Y. Chan. Department of Surgery, The University of Hong Kong, 102 Pokfulam Road, Hong Kong, China.

Email: acchan@hku.hk.

Background: The $8^{\text {th }}$ edition of the American Joint Committee on Cancer tumor-node-metastasis staging system (AJCC $8^{\text {th }}$ ) has been launched with modifications in T staging. The University of Hong Kong liver cancer staging system (HKUSS) has been proven to better categorize hepatocellular carcinoma (HCC) into different $T$ stages. This study aimed to compare the two systems' predictive ability for HCC recurrence after primary surgical resection.

Methods: Patients who had primary, curative resection for HCC between 1989 and 2017 were reviewed. The Kaplan-Meier plot was used to estimate disease-free survival (DFS), and the log-rank test was used for survival comparison between subgroups. The two systems' prediction of recurrence was evaluated by the Cox regression model.

Results: Totally 1,815 patients were included. With AJCC $8^{\text {th }}$, the 5 -year DFS was $58.9 \%$ for T1a, $52.3 \%$ for $\mathrm{T} 1 \mathrm{~b}, 30 \%$ for $\mathrm{T} 2,16.9 \%$ for $\mathrm{T} 3$, and $14.4 \%$ for $\mathrm{T} 4$. No survival difference was demonstrated between T1a and T1b $(\mathrm{P}=0.668)$ or between T3 and T4 $(\mathrm{P}=0.562)$. With HKUSS, the 5 -year DFS was $57.7 \%$ for $\mathrm{T} 1,43.4 \%$ for $\mathrm{T} 2,28.9 \%$ for $\mathrm{T} 3$, and $15.7 \%$ for $\mathrm{T} 4$. The $\mathrm{T}$ staging in HKUSS showed significant survival differences (T1 vs. T2, T2 vs. T3, and T3 vs. T4; $\mathrm{P}<0.001)$. Using receiver operating characteristic curves to show the recurrence status in the two systems, HKUSS had the largest area under curve (AUC) (HKUSS: $\mathrm{AUC}=0.655$, SE $0.014, \mathrm{P}<0.001,95 \%$ CI, 0.628-0.681; AJCC $8^{\text {th }}:$ AUC $=0.652, \mathrm{SE} 0.013, \mathrm{P}<0.001,95 \%$ CI, $0.625-0.677)$.

Conclusions: HKUSS showed better categorization of HCC. In the context of primary surgical resection, HKUSS may be more appropriate for stratification of patients with HCC with various T stages, and thus the choice of staging system when primary surgical resection is considered for patients of HCC.

Keywords: Hepatocellular carcinoma (HCC); HKU staging system; $8^{\text {th }}$ AJCC TNM staging; Liver Cancer Study Group of Japan; disease-free survival (DFS)

Submitted Nov 23, 2020. Accepted for publication Mar 31, 2021.

doi: 10.21037/atm-20-7611

View this article at: http://dx.doi.org/10.21037/atm-20-7611

^ ORCID: Wong Hoi She, 0000-0003-2049-3140; Albert Chi Yan Chan, 0000-0002-1383-2952; Ka Wing Ma, 0000-0002-6072-4874; Wing Chiu Dai, 0000-0002-2405-1641; Kenneth Siu Ho Chok, 0000-0001-7921-3807; Tan To Cheung, 0000-0002-2633-5883; Chung Mau Lo, 0000-00023964-5995. 


\section{Introduction}

Hepatocellular carcinoma (HCC) is the third leading cause of cancer-related deaths worldwide (1). Each year, 50,000 to $1,000,000$ patients are newly diagnosed and approximately 600,000 patients die of it globally $(2,3)$. Liver resection and liver transplantation are the best treatment options that attain long-term survival. However, even after potentially curative surgical extirpation, the 5 -year survival rates are only $54.8 \%$ (4) and $70 \%$ respectively (5). Because of the scarcity of liver grafts, liver transplantation is not considered as the first-line treatment option. Liver resection remains as the gold standard but the long-term prognosis is often influenced by postoperative tumor recurrence (6). Staging systems categorize patients with cancer into cohorts based on the severity and extent of the disease and predict survival in each category. Hence, a proper tumor staging of the disease allows an accurate stratification of patients for suitable management, enabling the patients to have a realistic expectation about their disease.

Currently, there are two categories of staging system, clinical and pathological. A clinical system stages the disease with clinical parameters and radiological details, whereas a pathological system stages the disease with final pathological results obtained after surgery with curative intent. To date, there are two commonly used pathological staging systems: one was the consensus reached by the American Hepato-Pancreato-Biliary Association and the American Joint Committee on Cancer (AJCC) (7), and the Liver Cancer Study Group of Japan also developed its staging system (LCSGJ) (8). Both systems use TNM as parameters to stage the disease-T: tumor (tumor size, tumor number, and nearby invasion); $\mathrm{N}$ : node (regional lymph node involvement); $\mathrm{M}$ : metastasis (distant metastasis). The AJCC has released the $8^{\text {th }}$ edition of its TNM staging system (AJCC $8^{\text {th }}$ ) (9) (Table 1). The major change is the subclassification of the T1 stage into T1a and T1b, depending on the size of the early small HCCs. There are also changes about $\mathrm{T} 2$ and $\mathrm{T} 3$, depending on tumor size, tumor number, and vascular invasion.

The University of Hong Kong liver cancer staging system (HKUSS) was based on the results of multivariable analysis of the clinical and pathological statuses of the patients. Microvascular invasion, tumor size and number, lobar distribution and symptomatic presentation impacted survival the most and formed the foundation of the HKUSS. The formulated HKUSS was validated with another group of HCC patients, which were not included in
Table 1 Descriptions of the different $T$ stages of primary liver cancer in HKUSS and AJCC $8^{\text {th }}$

\section{HKUSS}

T1 Single tumor $\leq 5.0 \mathrm{~cm}$, no microvascular invasion

T2 Single tumor $>5.0 \mathrm{~cm}$, no microvascular invasion

Or single tumor $\leq 5.0 \mathrm{~cm}$ plus microvascular invasion

Or unilobar multiple tumors, no microvascular invasion

T3 Single tumor $>5.0 \mathrm{~cm}$ plus microvascular invasion

T4 Unilobar multiple tumors plus microvascular invasion

Or bilobar tumors

Or tumor invasion of a branch of the portal or hepatic vein

Or tumor invasion of an adjacent organ except the gallbladder or rupture into the peritoneal cavity

AJCC $8^{\text {th }}$

T1a Solitary tumor $\leq 2 \mathrm{~cm}$ with/without vascular invasion

T1b Solitary tumor $>2 \mathrm{~cm}$, no vascular invasion

T2 Solitary tumor $>2 \mathrm{~cm}$ plus vascular invasion

Or multiple tumors $\leq 5 \mathrm{~cm}$

T3 Multiple tumors and $>5 \mathrm{~cm}$

Tumor(s) involving a major branch of the portal or hepatic vein with direct invasion of adjacent organ(s) (including the diaphragm) other than the gallbladder or with perforation of visceral peritoneum

HKUSS, The University of Hong Kong liver cancer staging system; AJCC $8^{\text {th }}$, the $8^{\text {th }}$ edition of the American Joint Committee on Cancer tumor-node-metastasis staging system. Adapted with permission from (10).

the initial test set. Results have shown that various $T$ stages in HKUSS were statistically different from each other and that it is a better staging system, with a greater area under curve (AUC), suggestive of better predictability for disease recurrence as compared with other staging systems (10) (Table 1).

This study had two objectives in the context of primary surgical resection for HCC. The first one was to evaluate the prognostic value of AJCC $8^{\text {th }}$, using a population-based data set. The second one was to compare HKUSS with other staging systems in terms of prognostic ability.

\section{Methods}

The study was conducted in accordance with the Declaration of Helsinki (as revised in 2013). Institutional review board 
approval was not obtained for this retrospective study, as according to local regulations, institutional review board approval is not required for retrospective studies analyzing anonymous data. All patients gave their written informed consent to collection and use of their data for research purposes. No individual patients can be identified with the anonymous data used in this study.

Clinicopathological data of all patients having primary, curative intent resection of HCC at our hospital from January 1989 to December 2017 were reviewed. Data were censored in December 2017. Patients who were intraoperatively found to have metastasis with metastasectomy performed $(n=2)$, who had positive resection margins $(n=98)$, and who died after the operation $(n=57)$ were not included. The operative technique for hepatic resection was reported previously (4). Major resection was defined as resection of more than three liver segments.

AJCC $8^{\text {th }}$ made a few changes to the $T$ classification in the $7^{\text {th }}$ edition $(9,11)$. The staging of early HCC was changed in AJCC $8^{\text {th }}$, which divided T1 into T1a and T1b (9). Details of the $\mathrm{T}$ classification in AJCC $8^{\text {th }}$ are shown in Table 1.

Major vascular invasion was defined as tumor invasion of the first branch of the portal vein or the first tributary of the hepatic vein. Microvascular invasion was defined as the existence of tumorous emboli in the tributaries of the hepatic or portal vein and only referred to the predominant tumor nodule. Tumor invasion of adjacent organs (other than the gallbladder) would be confirmed by visual inspection and examination and/or histological examination. Ruptured HCC was defined as the presence of peritumoral hematoma. Routine lymphadenectomy was not conducted since lymph node metastasis was not common in resectable HCC $(12,13)$. The prognostic effect of lymph node metastasis could not be assessed because of a lack of sufficient data, so only T staging was evaluated.

In this study, HKUSS was used as validation and comparison, using the same cohort of patients included in the authors' center. Our proposed T staging was described previously (10). In HKUSS, solitary tumor $\leq 5.0 \mathrm{~cm}$ without microvascular invasion was classified as T1. As the 5-year survival rates were similar in patients with a solitary tumor $\leq 5.0 \mathrm{~cm}$ and microvascular invasion, those with a solitary tumor $>5.0 \mathrm{~cm}$ and no microvascular invasion, and those with unilobar multiple tumors but no microvascular invasion, these conditions were all classified as T2. T3 disease was defined as solitary tumor $>5.0 \mathrm{~cm}$ plus microvascular invasion, whereas unilobar multiple tumors plus microvascular invasion and bilobar tumors were classified as T4 disease. The following conditions were also classified as T4: ruptured tumor, invasion of adjacent organs, invasion of a branch of the portal vein or hepatic vein, and symptomatic presentation (10) (Table 1).

LCSGJ is another widely accepted pathological staging system for HCC $(14,15)$. In short, the staging of T1T4 tumors involves only 3 criteria: $<2$ or $\geq 2 \mathrm{~cm}$, presence or absence of vascular invasion, and single or multiple tumors. Analysis of the cohort with LCSGJ was also used to compare its power of $\mathrm{T}$ stage stratification against AJCC $8^{\text {th }}$ and HKUSS.

The follow-up protocol was previously described (10). Computed tomography or magnetic resonance imaging was performed at one month for confirmation of macroscopic tumor clearance and then every three months. Serum liver biochemistry check was done every month in the first year and every three months afterwards. Tumor recurrence was defined as new lesion found on computed tomography or magnetic resonance imaging. Biopsy was generally avoided. There were no patients lost to follow-up.

Statistical analysis was performed using SPSS, version 20.0 (IBM SPSS Statistics; IBM Corporation, Armonk, New York, USA). Continuous variables were shown as median with range. The Mann-Whitney U test was employed to compare continuous variable between groups. Fisher's exact test or $\chi^{2}$ test was used to compare categorical variables. The KaplanMeier plot was adopted to estimate overall survival (OS) and disease-free survival (DFS). The log-rank test compared survival between subgroups. The primary endpoint was DFS, which was the length of time between operation and recurrence or death related to the disease/any complication of liver failure. OS was defined as the length of time between operation and death from any cause. Statistical significance was denoted by $\mathrm{P}$ value $<0.05$. Cox regression analysis was performed to evaluate the correlation between DFS and each staging system. Receiver operating characteristic (ROC) curves were constructed for various staging systems - HKUSS, LCSGJ, and the $5^{\text {th }}, 6^{\text {th }}, 7^{\text {th }}$ and $8^{\text {th }}$ editions of the AJCC system - in order to evaluate the AUC of the staging systems in predicting the risk of disease recurrence.

\section{Results}

The study analyzed 1,815 patients (1,459 males and 356 females), with a median age of 58 years. Their demographic, operative and pathological details are shown in Table 2. Terminal malignancy $(n=694,73 \%)$, variceal bleeding $(n=48,5 \%)$ and liver failure $(n=32,3.4 \%)$ were 
Table 2 Demographic, operative and pathological details of the 1,815 patients in different $T$ stages in HKUSS

\begin{tabular}{|c|c|c|c|c|c|c|c|c|c|c|c|}
\hline Details & \multicolumn{2}{|r|}{ Total } & \multicolumn{2}{|r|}{ T1 } & \multicolumn{2}{|r|}{$\mathrm{T} 2$} & \multicolumn{2}{|r|}{ T3 } & \multicolumn{2}{|r|}{$\mathrm{T} 4$} & $\begin{array}{c}P \\
\text { value }\end{array}$ \\
\hline Number & 1,815 & 100 & 517 & 28.5 & 524 & 28.9 & 178 & 9.8 & 596 & 32.8 & \\
\hline Male:female & & $4: 1$ & & $4: 1$ & & $4: 1$ & & $3: 1$ & & $6: 1$ & 0.002 \\
\hline Male & 1,459 & 80.4 & 406 & 78.5 & 416 & 79.4 & 131 & 73.6 & 506 & 84.9 & \\
\hline $\begin{array}{l}\text { Age (years), median } \\
\text { (range) }\end{array}$ & 1,815 & $\begin{array}{c}58 \\
{[18-89]}\end{array}$ & 517 & $\begin{array}{c}59 \\
{[19-84]}\end{array}$ & 524 & $\begin{array}{c}59.5 \\
{[18-86]}\end{array}$ & 178 & $\begin{array}{c}57 \\
{[28-83]}\end{array}$ & 596 & $\begin{array}{c}57 \\
{[19-89]}\end{array}$ & 0.002 \\
\hline $\begin{array}{l}\text { Body weight }(\mathrm{kg}) \text {, median } \\
\text { (range) }\end{array}$ & 1,808 & $\begin{array}{c}62 \\
(31.5-129.2)\end{array}$ & 516 & $\begin{array}{c}63.65 \\
(31.5-102.6)\end{array}$ & 522 & $\begin{array}{c}64 \\
{[34-110]}\end{array}$ & 175 & $\begin{array}{c}60.5 \\
(40-129.2)\end{array}$ & 595 & $\begin{array}{c}60 \\
(38-105.1)\end{array}$ & $<0.001$ \\
\hline $\begin{array}{l}\text { Body height }(\mathrm{cm}), \text { median } \\
\text { (range) }\end{array}$ & 1,745 & $\begin{array}{c}164 \\
{[136-190]}\end{array}$ & 501 & $\begin{array}{c}164 \\
(141.5-183)\end{array}$ & 506 & $\begin{array}{c}164.5 \\
{[140-187]}\end{array}$ & 168 & $\begin{array}{c}164 \\
{[137-182]}\end{array}$ & 570 & $\begin{array}{c}164.5 \\
{[136-190]}\end{array}$ & 0.148 \\
\hline \multicolumn{12}{|l|}{ Hepatitis } \\
\hline HBsAg (positive) & 1,519 & 83.7 & 457 & 88.4 & 425 & 81.1 & 134 & 75.3 & 503 & 84.4 & $<0.001$ \\
\hline HCV (positive) & 74 & 4.1 & 28 & 5.4 & 22 & 4.2 & 5 & 2.8 & 19 & 3.2 & 0.232 \\
\hline Grouping & & & & & & & & & & & $<0.001$ \\
\hline HBV only & 1,507 & 83 & 453 & 87.6 & 420 & 80.2 & 133 & 74.7 & 501 & 84.1 & $<0.001$ \\
\hline HCV only & 62 & 3.4 & 24 & 4.6 & 17 & 3.2 & 4 & 2.2 & 17 & 2.9 & $<0.001$ \\
\hline Both HBV and HCV & 12 & 0.7 & 4 & 0.8 & 5 & 1 & 1 & 0.6 & 2 & 0.3 & 0.307 \\
\hline Non-HBV, Non-HCV & 234 & 12.9 & 36 & 7 & 82 & 15.6 & 40 & 22.5 & 76 & 12.8 & $<0.001$ \\
\hline 2 groups & & & & & & & & & & & $<0.001$ \\
\hline $\begin{array}{l}\text { Non-cirrhotic/chronic } \\
\text { hepatitis }\end{array}$ & 746 & 41.1 & 165 & 31.9 & 219 & 41.8 & 98 & 55.1 & 264 & 44.1 & \\
\hline Cirrhosis & 1,071 & 58.9 & 352 & 68.1 & 305 & 58.2 & 80 & 44.9 & 334 & 55.9 & \\
\hline Child-Pugh class & & & & & & & & & & & 0.066 \\
\hline Class A & 1,751 & 96.4 & 505 & 97.7 & 508 & 96.9 & 171 & 96.1 & 567 & 94.8 & \\
\hline Class B & 66 & 3.6 & 12 & 2.3 & 16 & 3.1 & 7 & 3.9 & 31 & 5.2 & \\
\hline $\begin{array}{l}\text { ICG at } 15 \text { min (\%), median } \\
\text { (range) }\end{array}$ & 1,653 & $\begin{array}{c}10.7 \\
(1.2-78)\end{array}$ & 459 & $\begin{array}{c}10.6 \\
(1.2-78)\end{array}$ & 463 & $\begin{array}{c}10.6 \\
(1.3-64.2)\end{array}$ & 171 & $\begin{array}{c}10.8 \\
(2.5-55.5)\end{array}$ & 560 & $\begin{array}{c}10.7 \\
(1.6-42.5)\end{array}$ & 0.707 \\
\hline $\begin{array}{l}\text { AFP }(\mathrm{ng} / \mathrm{mL}) \text {, median } \\
\text { (range) }\end{array}$ & 1,808 & $\begin{array}{c}53.95 \\
(1-1,335,900)\end{array}$ & 516 & $\begin{array}{c}23 \\
(2-32,843)\end{array}$ & 520 & $\begin{array}{c}29.05 \\
(1-835,700)\end{array}$ & 178 & $\begin{array}{c}90 \\
(2-1,043,700)\end{array}$ & 594 & $\begin{array}{c}214.5 \\
(1.8-1,335,900)\end{array}$ & $<0.001$ \\
\hline
\end{tabular}

Table 2 (continued) 
Table 2 (continued)

\begin{tabular}{|c|c|c|c|c|c|c|c|c|c|c|c|}
\hline Details & \multicolumn{2}{|r|}{ Total } & \multicolumn{2}{|r|}{$\mathrm{T} 1$} & \multicolumn{2}{|r|}{$\mathrm{T} 2$} & \multicolumn{2}{|r|}{ T3 } & \multicolumn{2}{|r|}{$\mathrm{T} 4$} & $\begin{array}{c}\mathrm{P} \\
\text { value }\end{array}$ \\
\hline INR, median (range) & 1,786 & $1.1(0.8-1.8)$ & 512 & $1.1(0.9-1.6)$ & 519 & $1.1(0.8-1.5)$ & 170 & $1(0.8-1.3)$ & 585 & $1.1(0.8-1.8)$ & 0.138 \\
\hline $\begin{array}{l}\text { Creatinine }(\mu \mathrm{mol} / \mathrm{L}) \text {, } \\
\text { median (range) }\end{array}$ & 1,815 & $84(31-948)$ & 517 & $86(35-839)$ & 524 & $85(38-948)$ & 178 & $83(52-198)$ & 596 & $83(31-168)$ & 0.063 \\
\hline $\begin{array}{l}\text { Albumin }(g / L) \text {, median } \\
\text { (range) }\end{array}$ & 1,815 & $41[17-56]$ & 517 & 42 [23-53] & 524 & 41 [23-54] & 178 & 40 [27-53] & 596 & $40[17-56]$ & $<0.001$ \\
\hline $\begin{array}{l}\text { SGOT }(\mu / L) \text {, median } \\
\text { (range) }\end{array}$ & 1,815 & $44(12-1,324)$ & 517 & $36(13-204)$ & 524 & $41(15-393)$ & 178 & $60.5(19-440)$ & 596 & $55(12-1,324)$ & $<0.001$ \\
\hline$\leq 2 \mathrm{~cm}$ & 230 & 12.7 & 156 & 30.2 & 61 & 11.6 & 0 & 0 & 13 & 2.2 & $<0.001$ \\
\hline$>2 \mathrm{~cm} \leq 5 \mathrm{~cm}$ & 720 & 39.7 & 361 & 69.8 & 216 & 41.2 & 0 & 0 & 143 & 24 & \\
\hline$>5 \mathrm{~cm}$ or diffuse & 865 & 47.7 & 0 & 0 & 247 & 47.1 & 178 & 100 & 440 & 73.8 & \\
\hline $\begin{array}{l}\text { Number of tumor, median } \\
\text { (range) }\end{array}$ & 1,815 & $\begin{array}{c}1 \\
(1-\text { multiple) }\end{array}$ & 517 & $1(1-1)$ & 524 & $\begin{array}{c}1 \\
(1-\text { multiple) }\end{array}$ & 178 & $1(1-1)$ & 596 & $\begin{array}{c}2 \\
\text { (1-multiple) }\end{array}$ & $<0.001$ \\
\hline Solitary & 1,359 & 74.9 & 517 & 100 & 419 & 80 & 178 & 100 & 245 & 41.1 & $<0.001$ \\
\hline Multiple & 456 & 25.1 & 0 & 0 & 105 & 20 & 0 & 0 & 351 & 58.9 & \\
\hline 2 & 187 & 10.3 & 0 & 0 & 56 & 10.7 & 0 & 0 & 131 & 22 & $<0.001$ \\
\hline Well & 334 & 18.4 & 152 & 29.4 & 108 & 20.6 & 17 & 9.6 & 57 & 9.6 & \\
\hline Moderate & 1,077 & 59.3 & 289 & 55.9 & 319 & 60.9 & 106 & 59.6 & 363 & 60.9 & \\
\hline Poor & 355 & 19.6 & 60 & 11.6 & 87 & 16.6 & 53 & 29.8 & 155 & 26 & \\
\hline Undifferentiated & 7 & 0.4 & 0 & 0 & 1 & 0.2 & 1 & 0.6 & 5 & 0.8 & \\
\hline Necrosis & 5 & 0.3 & 2 & 0.4 & 1 & 0.2 & 0 & 0 & 2 & 0.3 & \\
\hline Unknown & 13 & 0.7 & 5 & 1 & 2 & 0.4 & 1 & 0.6 & 5 & 0.8 & \\
\hline Microvascular invasion & 846 & 46.6 & 0 & 0 & 220 & 42 & 178 & 100 & 448 & 75.2 & $<0.001$ \\
\hline Macrovascular invasion & 139 & 7.7 & 0 & 0 & 0 & 0 & 0 & 0 & 139 & 23.3 & $<0.001$ \\
\hline Tumor rupture & 108 & 6 & 0 & 0 & 0 & 0 & 0 & 0 & 108 & 18.1 & $<0.001$ \\
\hline $\begin{array}{l}\text { Regional lymph nodes } \\
\text { involved }\end{array}$ & 10 & 0.6 & 0 & 0 & 2 & 0.4 & 0 & 0 & 8 & 1.3 & 0.005 \\
\hline
\end{tabular}

Table 2 (continued) 
Table 2 (continued)

\begin{tabular}{|c|c|c|c|c|c|c|c|c|c|c|c|}
\hline Details & \multicolumn{2}{|c|}{ Total } & \multicolumn{2}{|r|}{$\mathrm{T} 1$} & \multicolumn{2}{|r|}{ T2 } & \multicolumn{2}{|r|}{ T3 } & \multicolumn{2}{|r|}{ T4 } & $\begin{array}{c}\mathrm{P} \\
\text { value }\end{array}$ \\
\hline Distant metastasis & 0 & 0 & 0 & 0 & 0 & 0 & 0 & 0 & 0 & 0 & - \\
\hline \multicolumn{12}{|l|}{ Resection type } \\
\hline Minor & 816 & 45 & 379 & 73.3 & 272 & 51.9 & 32 & 18 & 133 & 22.3 & $<0.001$ \\
\hline Right hepatectomy & 516 & 28.4 & 82 & 15.9 & 167 & 31.9 & 86 & 48.3 & 181 & 30.4 & $<0.001$ \\
\hline Left hepatectomy & 111 & 6.1 & 23 & 4.4 & 31 & 5.9 & 16 & 9 & 41 & 6.9 & \\
\hline Extensive resection & 370 & 20.4 & 32 & 6.2 & 53 & 10.1 & 44 & 24.7 & 241 & 40.4 & \\
\hline $\begin{array}{l}\text { Operative blood } \\
\text { transfusion }\end{array}$ & 341 & 18.8 & 44 & 8.5 & 82 & 15.6 & 42 & 23.6 & 173 & 29 & $<0.001$ \\
\hline $\begin{array}{l}\text { Blood loss (L), median } \\
\text { (range) }\end{array}$ & 1,806 & $\begin{array}{c}0.7 \\
(0.01-30)\end{array}$ & 513 & $\begin{array}{c}0.5 \\
(0.01-14)\end{array}$ & 521 & $\begin{array}{c}0.6 \\
(0.01-15)\end{array}$ & 177 & $\begin{array}{c}0.9 \\
(0.1-11.56)\end{array}$ & 595 & $\begin{array}{c}1 \\
(0.01-30)\end{array}$ & $<0.001$ \\
\hline Overall complication rate & 402 & 22.1 & 86 & 16.6 & 110 & 21 & 46 & 25.8 & 160 & 26.8 & $<0.001$ \\
\hline $\begin{array}{l}\text { Hospital stay }(d), \text { median } \\
\text { (range) }\end{array}$ & 1,812 & 9 [2-198] & 515 & $7[2-113]$ & 523 & 8 [2-86] & 178 & $10[3-130]$ & 596 & $10[2-198]$ & $<0.001$ \\
\hline Mortality rate & 0 & 0 & 0 & 0 & 0 & 0 & 0 & 0 & 0 & 0 & - \\
\hline Recurrence & & & & & & & & & & & $<0.001$ \\
\hline
\end{tabular}

HKUSS, The University of Hong Kong liver cancer staging system; HBsAg, hepatitis B surface antigen; HCV, hepatitis C virus; HBV, hepatitis B virus; ICG, indocyanine green; AFP, $\alpha$-fetoprotein; INR, international normalized ratio; SGOT, serum glutamic oxaloacetic transaminase; SGPT, serum glutamic pyruvic transaminase; N, number.

the commonest causes of mortality. Table 3 shows the distribution of the 1,815 patients in different $\mathrm{T}$ stages in AJCC $8^{\text {th }}$ and LCSGJ.

Using HKUSS, the 1-, 3- and 5-year rates of DFS were $86.6 \%, 66.8 \%$ and $57.7 \%$ respectively in patients with $\mathrm{T} 1$ tumors, $72.5 \%, 54.8 \%$ and $43.4 \%$ respectively in patients with T2 tumors, $52.5 \%, 34.4 \%$ and $28.9 \%$ respectively in patients with T3 tumors, and $36.3 \%, 19.4 \%$ and $15.7 \%$, respectively in patients with $\mathrm{T} 4$ tumor $(\mathrm{P}<0.001)$. The 1 -, 3 - and 5 -year rates of OS were $98.4 \%, 91 \%$ and $83.9 \%$ respectively in patients with $\mathrm{T} 1$ tumors, $94.6 \%, 79.5 \%$ and
$68.0 \%$ respectively in patients with T2 tumors, $89.8 \%$, $62.3 \%$ and $45.5 \%$ respectively in patients with T3 tumors, and $75.7 \%, 46.4 \%$ and $31.5 \%$ respectively in patients with $\mathrm{T} 4$ tumors $(\mathrm{P}<0.001)$. DFS survival $(\mathrm{P}<0.001)$ and overall survival $(\mathrm{P}<0.001)$ were significantly different among groups (Table 4) (Figure 1A,B).

Using AJCC $8^{\text {th }}$, the 1-, 3- and 5-year rates of DFS were $84.8 \%, 69.7 \%$ and $58.9 \%$ respectively in patients with $\mathrm{T} 1 \mathrm{a}$ tumors, $83.0 \%, 62.3 \%$ and $52.3 \%$ respectively in patients with T1b tumors, $58.3 \%, 38.1 \%$ and $30.0 \%$ respectively in patients with T2 tumors, $32.8 \%, 20.7 \%$ and $16.9 \%$ 
Table 3 Distribution of the 1,815 patients in different T stages in AJCC $8^{\text {th }}$ and LCSGJ

\begin{tabular}{|c|c|c|c|c|c|c|c|c|c|c|c|c|}
\hline $\begin{array}{l}\text { Staging } \\
\text { systems }\end{array}$ & \multicolumn{2}{|c|}{ Total } & \multicolumn{2}{|c|}{$\mathrm{T} 1 \mathrm{a}$} & \multicolumn{2}{|c|}{$\mathrm{T} 1 \mathrm{~b}$} & \multicolumn{2}{|c|}{$\mathrm{T} 2$} & \multicolumn{2}{|c|}{ T3 } & \multicolumn{2}{|c|}{$\mathrm{T} 4$} \\
\hline $\operatorname{AJCC} 8^{\text {th }}$ & 1,815 & 100 & 211 & 11.6 & 604 & 33.3 & 520 & 28.7 & 193 & 10.6 & 287 & 15.8 \\
\hline LCSGJ & 1,815 & 100 & \multicolumn{2}{|c|}{119} & \multicolumn{2}{|c|}{6.6} & 720 & 39.7 & 688 & 37.9 & 288 & 15.9 \\
\hline
\end{tabular}

AJCC $8^{\text {th }}$, the $8^{\text {th }}$ edition of the American Joint Committee on Cancer tumor-node-metastasis staging system; LCSGJ, the Liver Cancer Study Group of Japan staging system; N, number.

Table 4 The study cohort's survival difference with different T stages in HKUSS, AJCC $8^{\text {th }}$, and LCSGJ

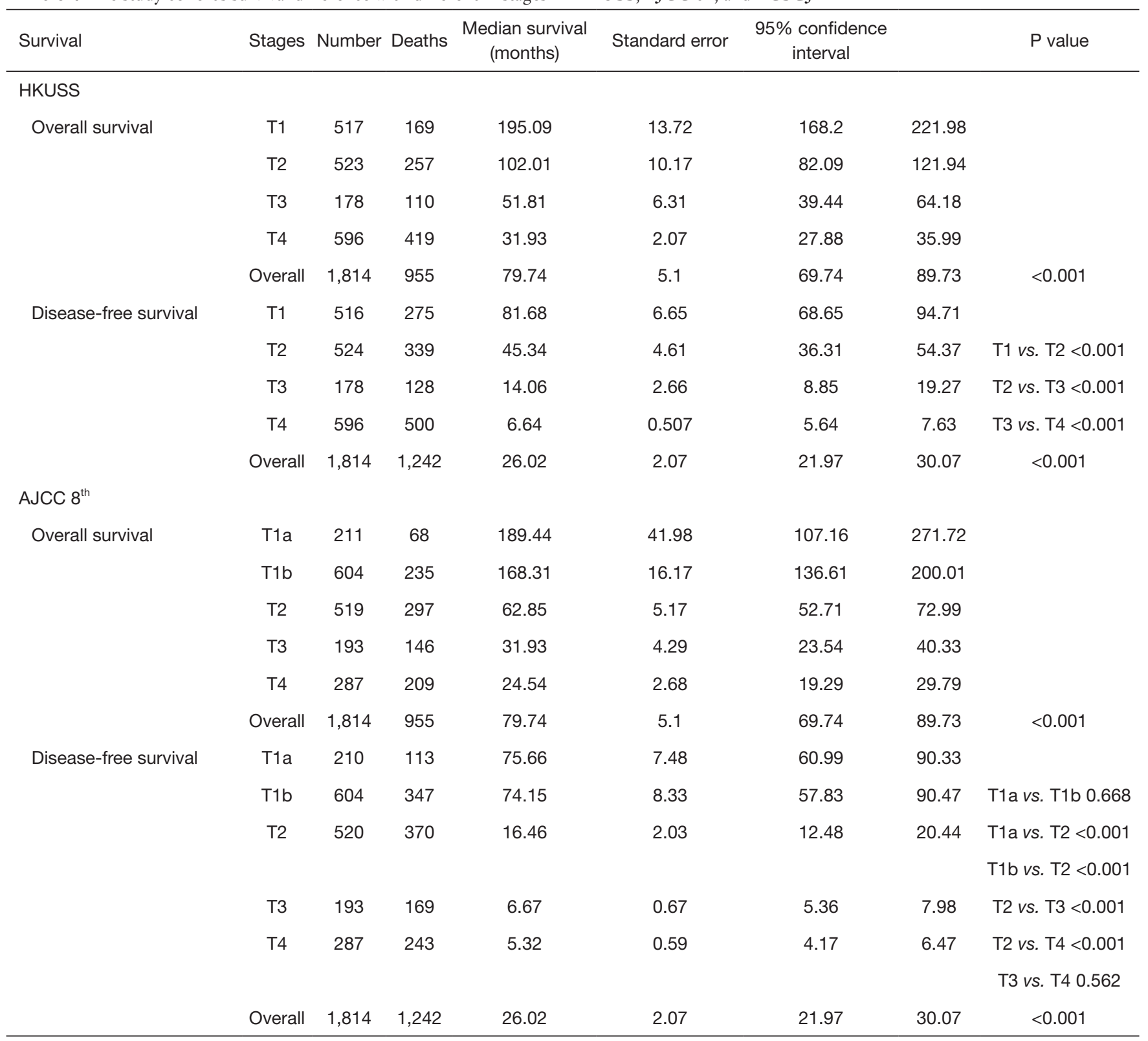

Table 4 (continued) 
Table 4 (continued)

\begin{tabular}{|c|c|c|c|c|c|c|c|c|}
\hline Survival & Stages & Number & Deaths & $\begin{array}{l}\text { Median survival } \\
\text { (months) }\end{array}$ & Standard error & $\begin{array}{c}95 \% \text { confidence } \\
\text { interval }\end{array}$ & & $P$ value \\
\hline \multicolumn{9}{|l|}{ LCSGJ } \\
\hline \multirow{2}{*}{ Overall survival } & $\mathrm{T} 2$ & 720 & 290 & 160.89 & 14.09 & 133.27 & 188.51 & \\
\hline & Overall & 1,814 & 955 & 79.74 & 5.1 & 69.74 & 89.73 & $<0.001$ \\
\hline \multirow[t]{3}{*}{ Disease-free survival } & $\mathrm{T} 1$ & 118 & 55 & 83.68 & 27.53 & 29.72 & 137.64 & \\
\hline & $\mathrm{T} 2$ & 720 & 420 & 67.88 & 6.54 & 55.06 & 80.7 & T1 vs. T2 0.053 \\
\hline & Overall & 1,814 & 1,242 & 26.02 & 2.07 & 21.97 & 30.07 & $<0.001$ \\
\hline
\end{tabular}

HKUSS, The University of Hong Kong liver cancer staging system; AJCC $8^{\text {th }}$, the $8^{\text {th }}$ edition of the American Joint Committee on Cancer tumor-node-metastasis staging system; LCSGJ, the Liver Cancer Study Group of Japan staging system.

respectively in patients with $\mathrm{T} 3$ tumors, and $31.7 \%, 17.1 \%$ and $14.4 \%$ respectively in patients with $\mathrm{T} 4$ tumor $(\mathrm{P}<0.001)$. The 1-, 3- and 5-year rates of OS were $98.1 \%, 90.4 \%$ and $82.9 \%$ respectively in patients with T1a tumors, $97.2 \%$, $87.3 \%$ and $78.6 \%$ respectively in patients with $\mathrm{T} 1 \mathrm{~b}$ tumors, $89.7 \%, 68.4 \%$ and $51.0 \%$ respectively in patients with $\mathrm{T} 2$ tumors, $86.9 \%, 47.6 \%$ and $34.3 \%$ respectively in patients with T3 tumors, and $65.4 \%, 38.1 \%$ and $26.7 \%$ respectively in patients with $\mathrm{T} 4$ tumors $(\mathrm{P}<0.001)$. There were significant survival differences between the T1a and $\mathrm{T} 2$ groups, between the $\mathrm{T} 1 \mathrm{~b}$ and $\mathrm{T} 2$ groups, between the $\mathrm{T} 2$ and $\mathrm{T} 3$ groups, and between the T2 and T4 groups. However, the survival difference between the $\mathrm{T} 1 \mathrm{a}$ and $\mathrm{T} 1 \mathrm{~b}$ groups $(\mathrm{P}=0.668)$ and that between the $\mathrm{T} 3$ and $\mathrm{T} 4$ groups $(\mathrm{P}=0.562)$ were not statistically significant (Table 4) (Figure 1C,D).

Using LCSGJ, the 1-, 3- and 5-year rates of DFS were $86.4 \%, 71.9 \%$ and $61.9 \%$ respectively in patients with $\mathrm{T} 1$ tumors, $81.0 \%, 61.1 \%$ and $51.5 \%$ respectively in patients with $\mathrm{T} 2$ tumors, $55.2 \%, 35.7 \%$ and $28.9 \%$ respectively in patients with $\mathrm{T} 3$ tumors, and $25.6 \%, 14.1 \%$ and $9.8 \%$ respectively in patients with $\mathrm{T} 4$ tumors $(\mathrm{P}<0.001)$. The 1-, 3 - and 5-year rates of OS were $99.2 \%, 91.7 \%$ and $87.3 \%$ respectively in patients with T1 tumors, $95.8 \%, 85 \%$ and $75.9 \%$ respectively in patients with $\mathrm{T} 2$ tumors, $87.5 \%$, $64.7 \%$ and $49.4 \%$ respectively in patients with $\mathrm{T} 3$ tumors, and $71.7 \%, 38 \%$ and $24.3 \%$ respectively in patients with $\mathrm{T} 4$ tumors $(\mathrm{P}<0.001)$. There were significant survival differences between the T1 and T3 groups, between the T2 and T3 groups, and between the T3 and T4 groups. Nevertheless, the survival difference was not significant between the $\mathrm{T} 1$ and $\mathrm{T} 2$ groups $(\mathrm{P}=0.053)$ (Table 4) (Figure 1E,F).

Using ROC curves to compare the $\mathrm{T}$ classifications in predicting the risk of recurrence, all the staging systems showed an AUC of $>0.648, \mathrm{P}<0.001$. Nonetheless, HKUSS showed the largest AUC of 0.655 , with a standard error of 0.014, 95\% CI, 0.628-0.681, $\mathrm{P}<0.001$ (Figure 2).

\section{Discussion}

The AJCC staging system was formulated on the basis of survival analysis of post-resection patients. An optimal staging system would allow accurate categorization of patients based on tumor biology, tumor status, and the extent of disease. Different stages should allow stratifying different disease statuses into different disease categories, hence giving patients a realistic expectation of DFS, or, if possible, OS. Unfortunately, to date, current staging systems mainly focus on pathological staging only, and thus the disease can only be staged after surgery. The TNM staging system developed by the AJCC has been updated 


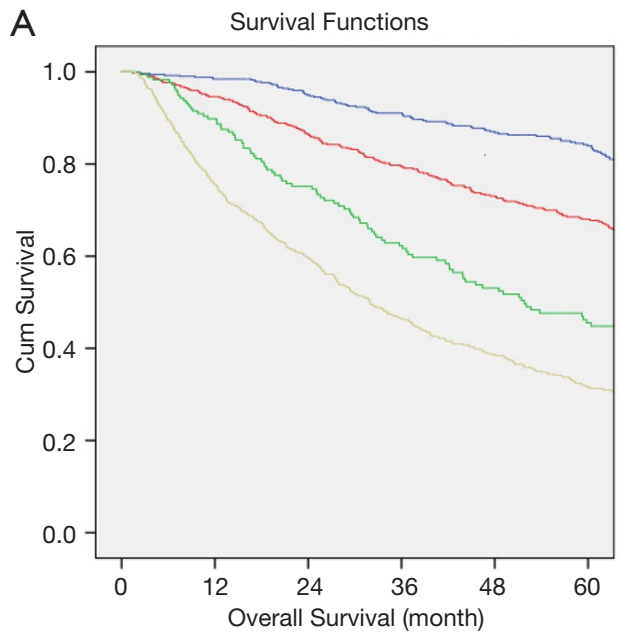

C

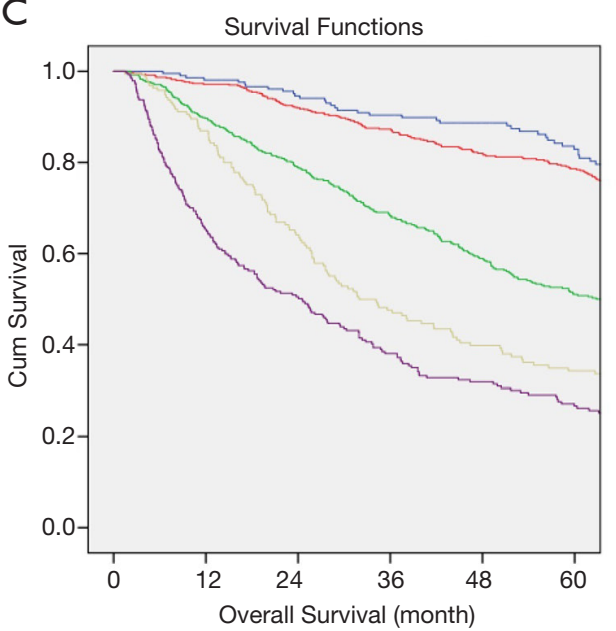

$\mathrm{E}$

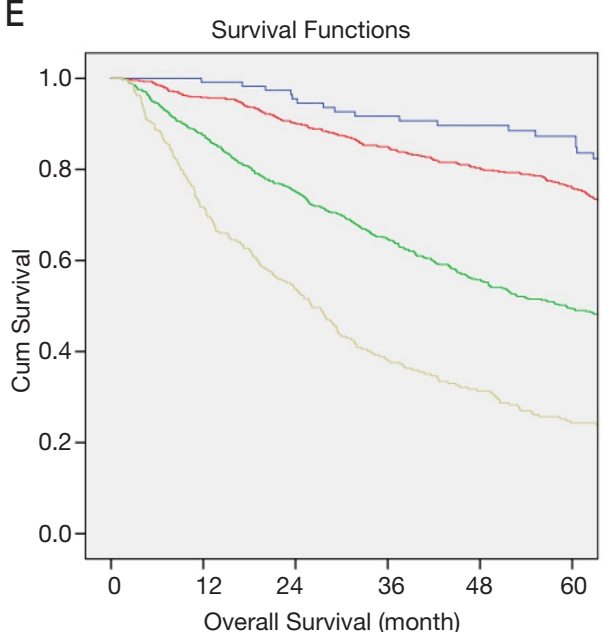

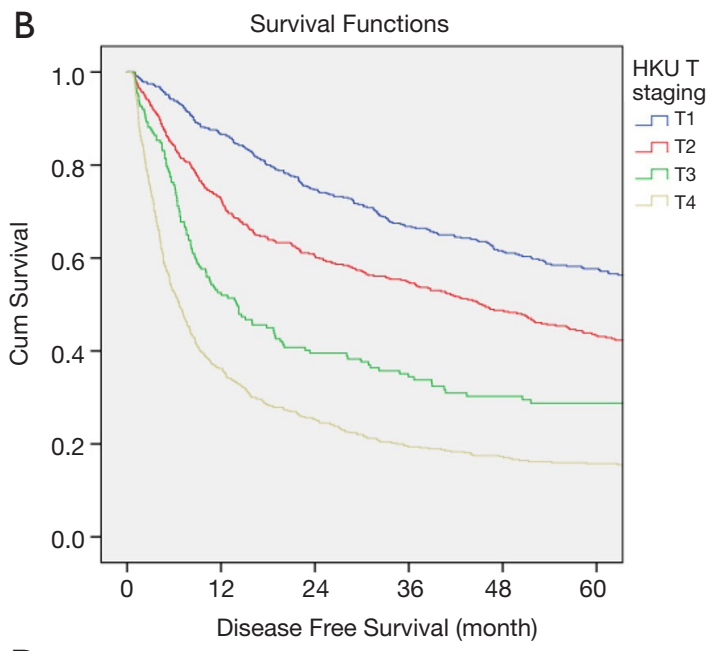

D
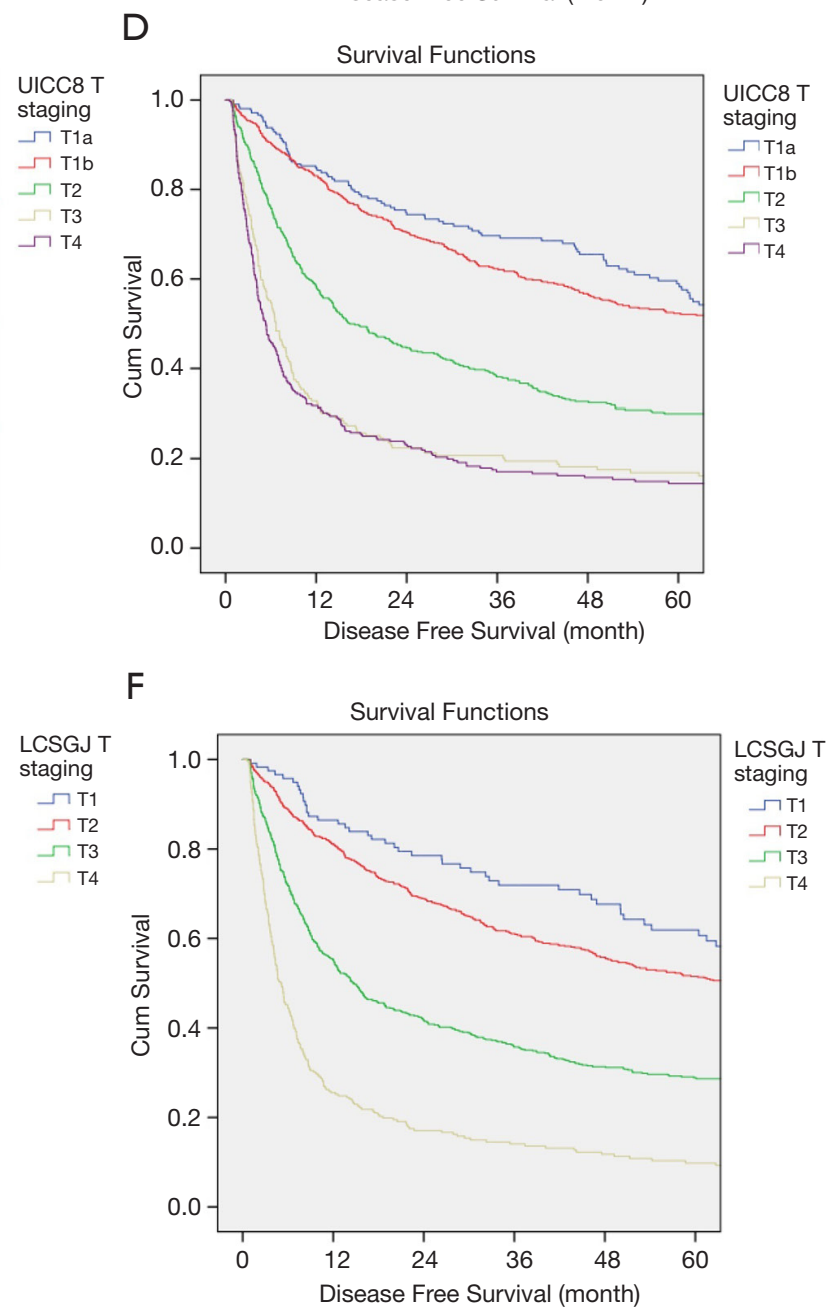

Figure 1 Overall survival and disease-free survival with various $T$ stages in The University of Hong Kong liver cancer staging system $(\mathrm{A}, \mathrm{B})$, the 8th edition of the American Joint Committee on Cancer tumor-node-metastasis staging system $(\mathrm{C}, \mathrm{D})$, and the Liver Cancer Study Group of Japan staging system (E,F) (HKU, The University of Hong Kong liver cancer staging system; UICC8, the 8th edition of the American Joint Committee on Cancer tumor-node-metastasis staging system; LCSGJ, the Liver Cancer Study Group of Japan staging system). 


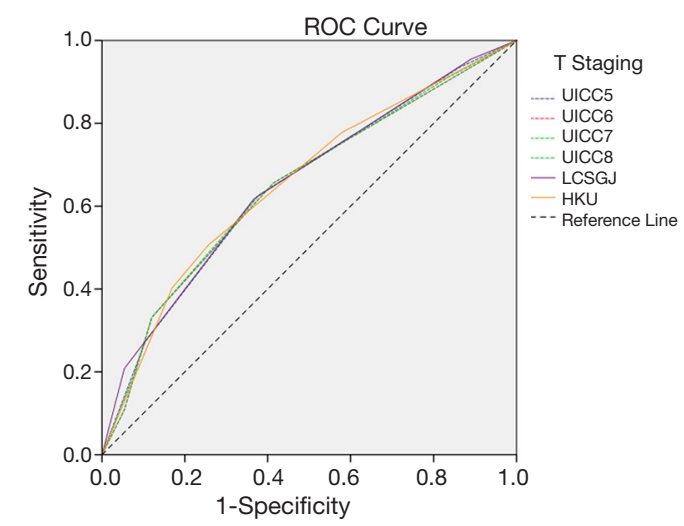

Figure 2 Receiver operating characteristic curves for various staging systems in predicting disease recurrence. (All $\mathrm{T}$ staging systems are significant with area under curve, while The University of Hong Kong liver cancer staging system and the Liver Cancer Study Group of Japan staging system are the two having the largest area under curve, followed by the $8^{\text {th }}$ edition, the $5^{\text {th }}$ edition, the $7^{\text {th }}$ edition and the $6^{\text {th }}$ edition of the American Joint Committee on Cancer tumor-node-metastasis staging system).

and validated regularly since its 1 st edition (16). The system was meant to provide information best on pathological characteristics of resected specimens. The $8^{\text {th }}$ edition was published in 2017. The major changes in this version included subcategorization of the $\mathrm{T}$ staging according to tumor size and presence/absence of vascular invasion (9). The present study evaluated the prognostic power of four editions of the AJCC staging system (the $5^{\text {th }}, 6^{\text {th }}, 7^{\text {th }}$ and $8^{\text {th }}$ editions) as well as LCSGJ. All of them failed to make adequate stratification of the patients into subgroups with distinct survival differences.

An ideal T staging system should have a good separation of $\mathrm{T}$ stages for different subsets of tumors. The inadequacy of the various staging systems has been briefly mentioned (10). In brief, the $7^{\text {th }}$ edition shows improvement in prognosis when compared with the editions before, but it still lacks enough power for prognosis of advanced-stage HCC (17). T3 tumors are divided into T3a (multiple tumors, any of which can be $>5.0 \mathrm{~cm}$ ) and $\mathrm{T} 3 \mathrm{~b}$ (tumor invasion of a major branch of the portal vein or the hepatic vein), but such subclassification of T3 tumors was shown to be unjustified, as the survival curves for T3a, T3b and T4 tumors were close to each other, signifying that these subgroups had very little difference in survival (10). This means the $7^{\text {th }}$ edition was unable to differentiate advanced disease, and thus specific adjuvant treatment targeting advanced stage disease would be lacking.

In AJCC $8^{\text {th }}$, early-stage T1 tumors were further subclassified into T1a and T1b, showing improvement of staging by shifting the focus of substratification to earlier HCC, which may allow patients with relatively common presentation of the disease to undergo more aggressive therapies. However, the survival curves for T1a and T1b approximated one another closely, signifying very slight survival differences in these two groups of patients without a definite need for subclassification. Therefore, the $2-\mathrm{cm}$ cutoff with absence of microvascular invasion might require further definition. Furthermore, in this analysis, the accuracy in staging more advanced disease did not achieve better substratification, as shown by the overlapping of the DFS survival curves for T3 and T4 diseases. Better refinement on the earlier and advanced stages is therefore needed.

With the same cohort of patients, the DFS curves for T1-T4 diseases in HKUSS showed distinct and even separation of stages. This suggests that the survival difference in HKUSS for all stages represented a more realistic estimation of the DFS, making HKUSS a better T staging system. In addition, the OS curves were also well separated. The distinct and even curve separations indicate better categorization of patients into the various groups based on tumor pathology.

For LCSGJ, despite the insignificant difference in DFS between $\mathrm{T} 1$ and $\mathrm{T} 2$ diseases, both the DFS and OS curves showed good separation of various $\mathrm{T}$ stages. LCSGJ had been proven to be able to make accurate stratification (18). Our result echoed the previous study and suggested that LCSGJ was also able to predict individual patient's prognosis. The use of LCSGHJ in this study was to further compare the $\mathrm{T}$ staging in different systems. Using $\mathrm{T}$ staging alone allowed better understanding of the treatment effect of surgery on specific tumor conditions. As seen from the ROC curves, LCSGJ performed almost as good as HKUSS.

Unfortunately, tumor burden, which is assessed radiologically only, is a poor surrogate of HCC's biological aggressiveness. Apart from pathological features such as poor differentiation and presence of microvascular or macrovascular invasion, behavior of a tumor may also be revealed by the serum proteins it produces. $\alpha$-fetoprotein has been used as a surrogate of tumor burden, which is also considered to be the tumor marker to monitor disease progression and treatment response (19). Des-ycarboxyprothrombin, an abnormal form of prothrombin, is mainly produced by HCC cells (20), and an increase of des-y-carboxyprothrombin has been shown to indicate a 
more aggressive tumor phenotype (21), the presence of microvascular invasion (22), and accelerated proliferation (23). It has been proposed that inflammatory markers such as neutrophil-to-lymphocyte ratio (24), platelet-to-lymphocyte ratio (25) and lymphocyte-to-monocyte ratio (26) be used to predict post-transplant HCC recurrence, OS, and waitlist dropouts. The Lens culinaris agglutinin fraction of $\alpha$-fetoprotein is a variant of $\alpha$-fetoprotein observed mainly in malignant cells (27) and it correlates with tumor size (28). Furthermore, dual-tracer (11C-acetate and $18 \mathrm{~F}$-fludeoxyglucose) positron emission tomography can increase sensitivity in HCC detection and predict the presence of microvascular invasion (29). These markers can be obtained preoperatively and are potentially useful for better stratification of patients in risk analyses, thereby offering better treatment options.

The current HKUSS was first proposed in 2012 (10). It has been shown to prognosticate DFS and OS more accurately. When HKUSS was formulated, only patients who had undergone surgery without preoperative evidence of metastasis and had been followed for more than 60 months were included. This reflected the genuine status of the $\mathrm{T}$ staging, and allowed sufficient time to monitor tumor behavior in each $\mathrm{T}$ stage after surgery. The experience of surgical management of patients with HCC at a single center allowed standardization of operative techniques and perioperative management, and therefore surgical outcomes (4). However, one might argue that generalization of the results might not be possible since variations in operative approaches might make a difference in long-term survival (30). To increase its generalizability, it would be most ideal to have the system externally validated by other centers. Anyway, additional patients recruited in the recent years had made the cohort larger, and hence the results of HKUSS more refined and thus more accurate. In this study, DFS was selected as the determinant of the performance of the staging systems, as DFS is more representative of underlying tumor characteristics and treatment outcomes from surgery itself, without the treatment effects from other therapies that would otherwise confound the analysis. On the other hand, if OS was set as the primary endpoint, survival comparison between different centers/places could hardly be fair and equal, since there would be a lack of standardization of treatment algorithms for postoperative tumor recurrence, and different forms of treatment (alone or combined) deployed for management of recurrent disease could have variable impact on OS, making it a confounding factor. In this study, it was seen that with surgery as the treatment,
HKUSS gave better prediction. HKUSS has continued to show a clear stratification of patients in both DFS and OS, which indicates that it is a clinically practicable staging system for HCC.

There are several pitfalls in this study. First, our patient population was predominantly affected by hepatitis B. Whether HKUSS is applicable to HCC with other etiologies needs further evaluation. By the same principle, HKUSS was derived solely from patients with preserved liver function who received liver resection. As a result, this system might not be applicable to non-surgical patients or patients with impaired liver function.

\section{Conclusions}

HKUSS showed better categorization of HCC. In the context of primary surgical resection, HKUSS may be more appropriate for stratification of patients with HCC with various $T$ stages, and thus the choice of staging system when primary surgical resection is considered for HCC patients.

\section{Acknowledgments}

The authors would like to thank Miss KWAN Lok Yan, Crystal, for data entry and statistical analysis.

Funding: None.

\section{Footnote}

Data Sharing Statement: Available at http://dx.doi. org/10.21037/atm-20-7611

Conflicts of Interest: All authors have completed the ICMJE uniform disclosure form (available at http://dx.doi. org/10.21037/atm-20-7611). The authors have no conflicts of interest to declare.

Ethical Statement: The authors are accountable for all aspects of the work (including full data access, integrity of the data and the accuracy of the data analysis) in ensuring that questions related to the accuracy or integrity of any part of the work are appropriately investigated and resolved. The study was conducted in accordance with the Declaration of Helsinki (as revised in 2013). Institutional review board approval was not obtained for this retrospective study, as according to local regulations, institutional review board approval is not required for retrospective studies analyzing 
anonymous data. All patients gave their written informed consent to collection and use of their data for research purposes. No individual patients can be identified with the anonymous data used in this study.

Open Access Statement: This is an Open Access article distributed in accordance with the Creative Commons Attribution-NonCommercial-NoDerivs 4.0 International License (CC BY-NC-ND 4.0), which permits the noncommercial replication and distribution of the article with the strict proviso that no changes or edits are made and the original work is properly cited (including links to both the formal publication through the relevant DOI and the license). See: https://creativecommons.org/licenses/by-nc-nd/4.0/.

\section{References}

1. Ferlay J, Colombet M, Soerjomataram I, et al. Estimating the global cancer incidence and mortality in 2018: GLOBOCAN sources and methods. Int J Cancer 2019;144:1941-53.

2. Nordenstedt H, White DL, El-Serag HB. The changing pattern of epidemiology in hepatocellular carcinoma. Dig Liver Dis 2010;42 Suppl 3:S206-14.

3. Sherman M. Hepatocellular carcinoma: epidemiology, risk factors, and screening. Semin Liver Dis 2005;25:143-54.

4. Fan ST, Mau Lo C, Poon RT, et al. Continuous improvement of survival outcomes of resection of hepatocellular carcinoma: a 20-year experience. Ann Surg 2011;253:745-58.

5. Chan SC, Cheung TT, Chan AC, et al. New insights after the first 1000 liver transplantations at The University of Hong Kong. Asian J Surg 2016;39:202-10.

6. Poon RT, Ng IO, Fan ST, et al. Clinicopathologic features of long-term survivors and disease-free survivors after resection of hepatocellular carcinoma: a study of a prospective cohort. J Clin Oncol 2001;19:3037-44.

7. Henderson JM, Sherman M, Tavill A, et al. AHPBA/ AJCC consensus conference on staging of hepatocellular carcinoma: consensus statement. HPB (Oxford) 2003;5:243-50.

8. Group JLCS. General Rules for the Clinical and Pathological Study of Primary Liver Cancer, 2nd English edn. Tokyo: Kanehara 2003.

9. Amin MB, Greene FL, Edge SB, et al. The Eighth Edition AJCC Cancer Staging Manual: Continuing to build a bridge from a population-based to a more "personalized" approach to cancer staging. CA Cancer J Clin 2017;67:93-9.
10. Chan AC, Fan ST, Poon RT, et al. Evaluation of the seventh edition of the American Joint Committee on Cancer tumour-node-metastasis (TNM) staging system for patients undergoing curative resection of hepatocellular carcinoma: implications for the development of a refined staging system. HPB (Oxford) 2013;15:439-48.

11. Edge SB, Compton CC. The American Joint Committee on Cancer: the 7th edition of the AJCC cancer staging manual and the future of TNM. Ann Surg Oncol 2010;17:1471-4.

12. Sun HC, Zhuang PY, Qin LX, et al. Incidence and prognostic values of lymph node metastasis in operable hepatocellular carcinoma and evaluation of routine complete lymphadenectomy. J Surg Oncol 2007;96:37-45.

13. Ercolani G, Grazi GL, Ravaioli M, et al. The role of lymphadenectomy for liver tumors: further considerations on the appropriateness of treatment strategy. Ann Surg 2004;239:202-9.

14. Kudo M, Izumi N, Kokudo N, et al. Management of hepatocellular carcinoma in Japan: Consensus-Based Clinical Practice Guidelines proposed by the Japan Society of Hepatology (JSH) 2010 updated version. Dig Dis 2011;29:339-64.

15. Kudo M, Kitano M, Sakurai T, et al. General Rules for the Clinical and Pathological Study of Primary Liver Cancer, Nationwide Follow-Up Survey and Clinical Practice Guidelines: The Outstanding Achievements of the Liver Cancer Study Group of Japan. Dig Dis 2015;33:765-70.

16. Kee KM, Wang JH, Lin CY, et al. Validation of the 7th edition TNM staging system for hepatocellular carcinoma: an analysis of 8,828 patients in a single medical center. Dig Dis Sci 2013;58:2721-8.

17. Chun YH, Kim SU, Park JY, et al. Prognostic value of the 7th edition of the AJCC staging system as a clinical staging system in patients with hepatocellular carcinoma. Eur J Cancer 2011;47:2568-75.

18. Makuuchi M, Belghiti J, Belli G, et al. IHPBA concordant classification of primary liver cancer: working group report. J Hepatobiliary Pancreat Surg 2003;10:26-30.

19. Chan SL, Mo FK, Johnson PJ, et al. New utility of an old marker: serial alpha-fetoprotein measurement in predicting radiologic response and survival of patients with hepatocellular carcinoma undergoing systemic chemotherapy. J Clin Oncol 2009;27:446-52.

20. Liebman HA, Furie BC, Tong MJ, et al. Des-gammacarboxy (abnormal) prothrombin as a serum marker of primary hepatocellular carcinoma. N Engl J Med 1984;310:1427-31. 
21. Meguro M, Mizuguchi T, Nishidate T, et al. Prognostic roles of preoperative alpha-fetoprotein and des-gammacarboxy prothrombin in hepatocellular carcinoma patients. World J Gastroenterol 2015;21:4933-45.

22. Iguchi T, Shirabe K, Aishima S, et al. New Pathologic Stratification of Microvascular Invasion in Hepatocellular Carcinoma: Predicting Prognosis After Living-donor Liver Transplantation. Transplantation 2015;99:1236-42.

23. Ma XL, Zhu J, Wu J, et al. Significance of PIVKA-II levels for predicting microvascular invasion and tumor cell proliferation in Chinese patients with hepatitis B virus-associated hepatocellular carcinoma. Oncol Lett 2018;15:8396-404.

24. Halazun KJ, Hardy MA, Rana AA, et al. Negative impact of neutrophil-lymphocyte ratio on outcome after liver transplantation for hepatocellular carcinoma. Ann Surg 2009;250:141-51.

25. Zhao Y, Si G, Zhu F, et al. Prognostic role of platelet to lymphocyte ratio in hepatocellular carcinoma: a systematic review and meta-analysis. Oncotarget 2017;8:22854-62.

26. Mano Y, Yoshizumi T, Yugawa K, et al. Lymphocyte-to-

Cite this article as: She WH, Chan ACY, Ma KW, Dai WC, Chok KSH, Cheung TT, Lo CM. Critical appraisal of TNM versus HKU staging system for postoperative prognostic evaluation of hepatocellular carcinoma. Ann Transl Med 2021;9(11):919. doi: 10.21037/atm-20-7611
Monocyte Ratio Is a Predictor of Survival After Liver Transplantation for Hepatocellular Carcinoma. Liver Transpl 2018;24:1603-11.

27. Carr BI, Kanke F, Wise M, et al. Clinical evaluation of lens culinaris agglutinin-reactive alpha-fetoprotein and des-gamma-carboxy prothrombin in histologically proven hepatocellular carcinoma in the United States. Dig Dis Sci 2007;52:776-82.

28. Choi JY, Jung SW, Kim HY, et al. Diagnostic value of AFP-L3 and PIVKA-II in hepatocellular carcinoma according to total-AFP. World J Gastroenterol 2013;19:339-46.

29. Cheung TT, Chan SC, Ho CL, et al. Can positron emission tomography with the dual tracers [11 C] acetate and [18 F]fludeoxyglucose predict microvascular invasion in hepatocellular carcinoma? Liver Transpl 2011;17:1218-25.

30. Tanaka S, Mogushi K, Yasen M, et al. Surgical contribution to recurrence-free survival in patients with macrovascularinvasion-negative hepatocellular carcinoma. J Am Coll Surg 2009;208:368-74. 